\title{
re \\ ETIOLOGICAL PROFILE OF LOWER GASTROINTESTINAL BLEED IN A TERTIARY CARE HOSPITAL IN NORTHERN INDIA
}

\section{Bansal Arpit}

Mehrotra M K*

\section{Mowar A B}

\section{ABSTRACT}

INTRODUCTION - Lower Gastrointestinal(GI) bleeding refers to blood loss of recent onset originating from a site distal to the ligament of Treitz.1It usually presents as hematochezia i.e. passage of maroon or bright red blood or blood clots per rectum. Lower GI bleeding ( LGIB) accounts for almost $20 \%$ of all cases of acute GI bleeding.2 The etiology and the epidemiology of LGIB varies according to the environmental conditions depending upon the life style, dietary habits, the prevalence of smoking, history of drug intake, age and longevity of the population etc. 2 Most of the studies pertaining to the etiologies of Lower GI bleeding are from the West. Data relating to the incidence and etiologies of Lower GI bleed in India is scarce hence this study was undertaken to identify the etiological profile of patients presenting with Lower GI bleeding in a tertiary care hospital in the northern part of India.

MATERIALS AND METHODS - It is a Cross-sectional study done over a period of 1 year from January, 2018 to December, 2018. All the patients above 18 years of age with first presentation of Lower GI bleeding to the Department of Medicine, SRMS- IMS, Bareilly, Uttar Pradesh during the period of study are included in the study.

RESULTS - A total of 232 patients meeting the inclusion criteria were included in the study. Majority of the patients were males (69.8\%). Hematochezia ( $86 \%$ ) was the most common presenting feature and was commonly associated with constipation (46\%), abdominal pain (32\%) and loss of weight (11\%). $8 \%$ of the patients had a history of Diabetes. Alcohol consumption was seen in $17 \%$ of the patients while $26 \%$ of the patients had a history of smoking. The most common etiology of Lower GI bleed seen was Hemorrhoids (35.3\%), followed by Inflammatory Bowel disease $(16.3 \%)$, Malignancy $(12 \%)$ and Radiation proctosigmoiditis $(11.2 \%)$.

CONCLUSION - LGIB is a common and alarming presenting condition in the practice of gastroenterology. It was found that Lower GI bleed is more common in males, usually in the 3rd to 4th decade of life and most commonly presents with hematochezia. Haemorrhoids, IBD and Malignancy were the major causes of Lower GI bleed.

\section{KEYWORDS :}

\section{INTRODUCTION}

Lower gastrointestinal bleeding ( LGIB) refers to blood loss of recent onset originating from a site distal to the ligament of Treitz. It usually presents as hematochezia i.e. passage of maroon or bright red blood or blood clots per rectum. Lower GI hemorrhage accounts for almost $20 \%$ of all cases of acute GI bleeding. ${ }^{2}$ It has an annual incidence of hospitalization of approximately $36 / 100,000$ population. ${ }^{3}$ The incidence is higher in older patients and patients taking multiple medications.

The etiology and the epidemiology of LGIB varies according to the environmental conditions depending upon the life style, dietary habits, the prevalence of smoking, history of drug intake, age and longevity of the population etc. ${ }^{2}$ Lower intestinal bleeding has been found significantly more often in men than women and the incidence rate increases with age with a greater than 200 - fold increase from the third to the ninth decades of life.

The etiology of LGIB in adults is diverse, both in the anatomic position of causative lesion(s) and in the propensity of these lesions to cause clinically significant bleeding. The most common causes of LGIB are Diverticular (60\%), Inflammatory bowel disease (IBD), ischemic, others (13\%), Anorectal (11\%), Neoplasia (9\%), Coagulopathy (4\%) and angiodysplasia (3\%).

However, in the Indian experience, the etiology differs significantly. ${ }^{5}$ In comparison with the West, patients are younger, localization is possible in a majority of patients, mortality is lower and re-bleed rate is only $4 \%$. ${ }^{7}$ Nonspecific ulcers account for $30 \%$ of cases while the rest are enteric ulcers $15 \%$, tubercular ulcers $6 \%$, neoplasm $6 \%$, amoebic ulcers $6 \%$, angiodysplasia $6 \%$ and others.

Colonoscopy has been shown to correctly identify the source of LGIB in more than $75 \%$ of patients while also allowing a therapeutic modality at the same time.

Most of the studies pertaining to the etiologies of LGIB are from the west. Data relating to the incidence and etiologies of LGIB in India is scarce. Hence this study was undertaken to identify the etiological profile of patients presenting with Lower GI bleeding in a tertiary care hospital in the northern part of India.

\section{MATERIALSAND METHODS}

It is a Cross-sectional study done over a period of 1 year from $1^{\text {st }}$ January, 2018 to $31^{\text {st }}$ December, 2018.

\section{INCLUSION CRITERIA:}

All the patients above 18 years of age with first presentation of Lower GI bleeding to the Department of Medicine, SRMS- IMS, Bareilly, Uttar Pradesh during the period of study are included in the study.

\section{EXCLUSION CRITERIA:}

Patients unfit for Lower GI Video Endoscopy and those who did not give consent for the procedure were excluded from the study.

Ethical clearance was obtained from the Institutional Ethical Committee prior to the commencement of the study. A written informed consent was taken from all the participants after explaining the nature and purpose of the study. All patients were interviewed and subjected to a clinical examination. The data was recorded in a predesigned and pretested pro forma.

The participants underwent a lower gastrointestinal video endoscopy within 24 hours of presentation to the hospital using a forward viewing endoscope after adequate preparation prior to the procedure.

The data obtained was coded and entered into the Microsoft Excel spreadsheet. The categorical data was expressed as rates, ratios and percentages and continuous data was expressed as mean \pm standard deviation.

\section{RESULTS}

A total of 232 patients meeting the inclusion criteria were included in the study. Majority of the patients were males $(69.8 \%)$. The mean age 
of presentation was $46.14 \pm 19.72$ years. Most patients were between $18-30$ years of age $(25 \%)$.

Hematochezia (86\%) was the most common presenting feature and was commonly associated with constipation $(46 \%)$, abdominal pain $(32 \%)$ and loss of weight $(11 \%)$. Diabetes was present in $8 \%$ of the patients. Alcohol consumption was seen in $17 \%$ of the patients while $26 \%$ of the patients had a history of smoking.

On Lower GI endoscopy, the most common etiology of Lower GI bleed seen was Hemorrhoids 82(35.3\%) followed by IBD 38(16.3\%), Malignancy $28(12 \%)$ and Radiation Proctosigmoiditis 26(11.2\%). Other findings seen were Infective colitis $22(9.4 \%)$, Polyps $12(5.1 \%)$, Solitary Rectal Ulcer 10(4.3\%), Diverticulosis 6(2.5\%), Non - specific ulcers 4(1.7\%) and Ischemic colitis 4(1.7\%).

\section{Findings on Lower GI Endoscopy}
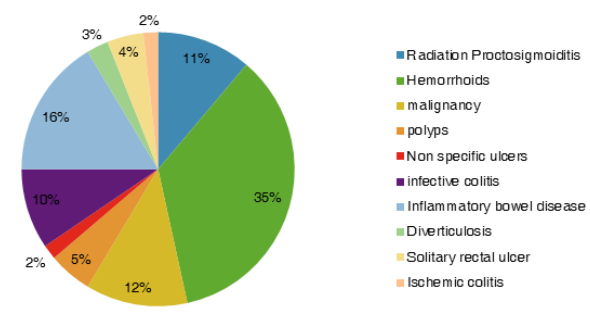

\section{DISCUSSION}

Lower GI bleeding is an alarming event. ${ }^{9}$ Lower GI bleeding is associated with significant morbidity and mortality. ${ }^{10}$ It can range from mild bleeding to life threatening hemorrhage. ${ }^{11}$

LGIB predominantly afflicts an older population with a mean age at presentation from 63 to 77 years. ${ }^{12,13}$ However in comparison with the West patients presenting with LGIB are younger in India. ${ }^{7}$ In our study most of the patients presenting with LGIB were middle aged between $3 \mathrm{rd}$ and $4^{\text {th }}$ decade of life. The mean age of presentation was 46.14 \pm 19.72 years which was similar to the study by Badiger RH et al ${ }^{14}$ and a study by Hajare $\mathrm{S}$ et $\mathrm{al}^{10}$.

In the present study, there was a male preponderance (69.8\%) among patients presenting with Lower GI bleed. It has been seen that lower GI bleed affects men more commonly than women as seen in a study conducted by Dar IA et $\mathrm{al}^{2}$ (59\% males), Shrestha UK et al ${ }^{11}(62 \%$ males) and Peura et $\mathrm{al}^{15}$. The male predominance can be attributed to tobacco use, alcohol consumption, low fibre diet, reduced fluid intake which increase colonic transit time and retain faecal wastage. ${ }^{16}$

Clinically, the most common presentation was Hematochezia (86\%) which was most commonly associated with constipation (46\%) while no patient had melena as a presenting feature of lower GI bleed in the present study. This was similar to the findings by Badiger et $\mathrm{al}^{14}$. In a study by Dar et $\mathrm{al}^{2}$ hematochezia was the commonest symptom in $63.3 \%$ patients followed by bloody diarrhoea $(17 \%)$, anorectal bleed $(12.3 \%)$ and melena $(7 \%)$. This difference in presentation can be explained by the different locations of bleeding source. ${ }^{2}$

The aetiology of lower GI bleed shows a marked geographical variation. Colonic polyps, Carcinoma and IBD constituted the three most common causes in various series from the West. ${ }^{17}$ In our study the most common cause of lower GI bleed was Hemorrhoids (35.3\%) followed by IBD (16.3\%), Malignancy $(12 \%)$ and radiation proctosigmoiditis $(11.2 \%)$. In the study by Hajare et $\mathrm{al}^{10}$ in Indian population haemorrhoids $(48 \%)$, ulcerative colitis $(24 \%)$ and carcinoma of the colon (10\%) were the important causes of LGIB on colonoscopy which are in line with our study. Shreshta et a ${ }^{11}$ found the aetiologies of LGIB to be hemorrhoids (35.2\%), non-specific colitis (24.8\%), colon polyps (18.3\%), IBD $(10.4 \%)$, colon cancer $(6.5 \%)$ in a study in 415 patients in Nepal. In a study by Dar IA et $\mathrm{al}^{2}$, in Jammu \& Kashmir, India the most common cause of LGIB was colorectal polyps (23.3\%), while IBD was seen in $17.7 \%$ cases and malignancy in $12 \%$.In a study conducted by Alruzug et al. ${ }^{16}$ in 1137 patients in Saudi Arabia, haemorrhoids (38.5\%), diverticulosis (12.1\%), and malignant neoplasms $(9.9 \%)$ were reported to be the most common findings on colonoscopy of LGIB. In another study done in Singapore, the most common etiology of LGIB was hemorrhoids. ${ }^{18}$

\section{CONCLUSION}

LGIB is a common and alarming presenting condition in practice of gastroenterology.

However, data regarding epidemiology of LGIB is scarce particularly from India. This study was conducted to shed some light in this regard. It was found that Lower GI bleeding is more common in males, usually in the $3^{\text {rd }}$ to $4^{\text {th }}$ decade of life and most commonly presents with hematochezia. Haemorrhoids, IBD and malignancy were the major causes of Lower GI bleeding. Studying the variations in the etiological profile in different geographical locations could guide us in a better understanding of the associated risk factors and pathogenesis and aid in improving patient outcome. Multicentre studies on larger patient populations are required to fully understand the aetiology of lower GI bleeding in various parts of the World.

\section{FUNDING SOURCE \\ Nil}

\section{CONFLICT OF INTEREST}

There is no conflict of interest

\section{REFERENCES}

1. Zuccaro G Jr. Management of the adult patient with acute lower gastrointestinal bleeding. American College of Gastroenterology. Practice Parameters Committee. Am J Gastroenterol 1998; 93:1202

2. Dar IA, Dar WR, Khan MA, Kasana BA, So NU, Hussain M, et al. Etiology, clinical presentation, diagnosis and management of lower gastrointestinal bleed in a tertiary care hospital in India: A retro-prospective study. J Dig Endosc 2015;6:101

3. Laine L, Yang H, Chang SC, Datto C. Trends for incidence of hospitalization and death due to GI complications in the United States from 2001 to 2009. Am J Gastroenterol. 2012;107:1190-5

4. Amin SK, Antunes C. Gastrointestinal Bleeding, Lower. [Updated 2018 Oct 27]. In: StatPearls [Internet]. Treasure Island (FL): StatPearls Publishing; 2019 Jan-. Available StatPearls [Internet]. Treasure Island (FL): StatPearls Pub/
from: https://www.ncbi.nlm.nih.gov/books/NBK448126/

5. Zuckerman GR, Prakash C. Acute lower intestinal bleeding: Part I: Clinical presentationand diagnosis. GastrointestEndosc 1998;48:606-17

6. Vernava AM, Longo WE, Virgo KS (1996) A nationwide study of the incidence and etiology of lower gastrointestinal bleeding. Surg Res Commun 18:113-120

7. Govil D, Sahni P. Lower Gastrointestinal Haemorrhage. GI Surgery Annual Vol 1994;13-103.

8. Khandelwal C. Lower gastrointestinal bleeding. Indian J Surg 2003;65:151-5

9. Sharma B, Sharma R, Bodh V, Sharma S, Sood A, Sharma R, Sharma N. Chronic lower gastrointestinal bleeding: Etiological profile and role of colonoscopy among children grom sub-Himalayan ranges of North India. J Dig Endosc 2018;9:109-13

10. Hajare S, Kantamaneni R. Etiological profile of patients with lower gastrointestinal bleeding: A 1-year cross-sectional study.Arch Med Health Sci 2018;6:300-2

11. Shrestha UK. Etiological profile, gender difference and age group patterns of 415 patients presenting with lower gastrointestinal bleeding in the western region of Nepal. J Adv Internal Med 2015;3:52-5.

12. Bounds BC, Kelsey PB. Lower gastrointestinal bleeding. GastrointestEndoscClin N Am 2007; $17: 273-88$

13. Farrell JJ, Friedman LS. Gastrointestinal bleeding in the elderly.GastrointestEndoscClin NAm 2001;30:377-407

14. Badiger RH, Hajare S, Kantamaneni R, Kole A, Deebanshu. Etiological profile of patients presenting with lower gastrointestinal bleeding at tertiary care hospital at Belagavi: a cross sectional study. Int J Adv Med 2017;4:1429-33.

15. Peura DA, Lanza FL, Gostout CJ, Foutch PG. The American College of Gastroenterology Bleeding Registry: Preliminary findings. Am J Gastroenterol 1997;92:924

16. Alruzug IM, Aldarsouny TA, Semaan T, AlMustafa A. Lower gastrointestinal bleeding in Saudi patients: A retrospective longitudinal study. J Gastrointest Digestive Sys 2016;6:410.

17. Goenka MK, Kochhar R, Mehta SK. Spectrum of lower gastrointestinal hemorrhage: an endoscopic study of 166 patients. Indian J Gastroenterol. 1993;12:129-131

18. Schmulewitz N, Fisher DA, Rockey DC. Early colonoscopy for acute lower GI bleeding predicts shorter hospital stay: a retrospective study of experience in a single centre. GastrointestEndosc. 2003;58:841-6. 